Supporting Information

\title{
Rapid, Surfactant-Free and Quantitative Functionalization of Gold Nanoparticles with Thiolated DNA under Physiological pH and Its Application in Molecular Beacon-Based Biosensor
}

\author{
Qing $\mathrm{Xu},{ }^{\dagger}$ Xinhui Lou, ${ }^{* \dagger}$ Lei Wang, ${ }^{\dagger}$ Xiaofan Ding, ${ }^{\dagger}$ Haixiang Yu, ${ }^{\ddagger}$ and Yi Xiao ${ }^{\ddagger}$ \\ ${ }^{\dagger}$ Department of Chemistry, Capital Normal University, Xisanhuan North Road. 105, \\ Beijing 100048, China \\ ${ }^{ \pm}$Department of Chemistry and Biochemistry, Florida International University, Miami, \\ Florida 33199, United States
}

Corresponding Author

*Email:xinhuilou@cnu.edu.cn

Tel: +86-10-68902491 ext. 808 .

Fax: +86-10-68902320. 
Table S1. DNA sequences used in this study

\begin{tabular}{|c|c|}
\hline Name & Sequence ( $5^{\prime}$ to $\left.3^{\prime}\right)$ \\
\hline $15-\mathrm{A}_{10}-\mathrm{SH}$ & TGGATGATGTGGTAT-A $\mathrm{A}_{10}-\mathrm{SH}$ \\
\hline $15-\mathrm{T}_{10}-\mathrm{SH}$ & TGGATGATGTGGTAT- $\mathrm{T}_{10}-\mathrm{SH}$ \\
\hline $15-\mathrm{EG}_{18}-\mathrm{SH}$ & TGGATGATGTGGTAT- $\left(\mathrm{CH}_{2} \mathrm{CH}_{2} \mathrm{O}\right)_{18}-\mathrm{SH}$ \\
\hline $15-\mathrm{EG}_{12}-\mathrm{SH}$ & TGGATGATGTGGTAT- $\left(\mathrm{CH}_{2} \mathrm{CH}_{2} \mathrm{O}\right)_{12}-\mathrm{SH}$ \\
\hline $15-\mathrm{EG}_{6}-\mathrm{SH}$ & TGGATGATGTGGTAT- $\left(\mathrm{CH}_{2} \mathrm{CH}_{2} \mathrm{O}\right)_{6}-\mathrm{SH}$ \\
\hline FAM-15- $\mathrm{A}_{10}-\mathrm{SH}$ & FAM-TGGATGATGTGGTAT-A $10-\mathrm{SH}$ \\
\hline FAM-15- $\mathrm{T}_{10}-\mathrm{SH}$ & FAM-TGGATGATGTGGTAT-T $10-\mathrm{SH}$ \\
\hline FAM-15-EG $18-\mathrm{SH}$ & FAM-TGGATGATGTGGTAT- $\left(\mathrm{CH}_{2} \mathrm{CH}_{2} \mathrm{O}\right)_{18}-\mathrm{SH}$ \\
\hline HS-EG $18-15$ & SH- $\left(\mathrm{CH}_{2} \mathrm{CH}_{2} \mathrm{O}\right)_{18}$-TATGGTGTAGTAGGT \\
\hline $30-\mathrm{EG}_{18}-\mathrm{SH}$ & $\begin{array}{l}\text { TATTATCTTGTGTCTTATGGTGTAGTAGGT- } \\
\left(\mathrm{CH}_{2} \mathrm{CH}_{2} \mathrm{O}\right)_{18}-\mathrm{SH}\end{array}$ \\
\hline $\mathrm{MB} 1-\mathrm{EG}_{18}-\mathrm{SH}$ & CGCTCCCTTATTATTATTCCGAGCG- $\left(\mathrm{CH}_{2} \mathrm{CH}_{2} \mathrm{O}\right)_{18}-\mathrm{SH}$ \\
\hline $\mathrm{MB} 1-\mathrm{T}_{10}-\mathrm{SH}$ & CGCTCCCTTATTATTATTCCGAGCG-T $_{10}-\mathrm{SH}$ \\
\hline FAM-MB2-EG $18-\mathrm{SH}$ & $\begin{array}{l}\text { FAM-GCTCGTGAGTTCATGCGACCAGGAAGGATTA } \\
\text { CGAGC- }\left(\mathrm{CH}_{2} \mathrm{CH}_{2} \mathrm{O}\right)_{18} \text {-SH }\end{array}$ \\
\hline FAM-MB2 target & AATCCTTCCTGGTCGCATGAACTC \\
\hline
\end{tabular}

FAM: fluorescein 
Table S2. Comparison of "aging-salting" process, low-pH method, and OEG-spacer assisted method

\begin{tabular}{|c|c|c|c|}
\hline Method & "aging-salting" & Low-pH method & OEG-spacer \\
\hline Time needed & $1-2 d$ & $3 \mathrm{~min}$ & $3 \mathrm{~min}$ \\
\hline $\mathrm{pH}$ & 7.4 & 3 & $3-10$ \\
\hline $\begin{array}{l}\text { Loading capacity at the } \\
\text { same salt concentration }\end{array}$ & Medium to High & Medium & High \\
\hline Quantitative loading & No & Yes & Yes \\
\hline $\begin{array}{l}\text { Suitability for DNA with } \\
\text { secondary structure }\end{array}$ & No & No & Yes \\
\hline $\begin{array}{l}\text { Control the conformation } \\
\text { of DNA on AuNP }\end{array}$ & Hard & Hard & Easy \\
\hline $\begin{array}{l}\text { Mechanism: minimize } \\
\text { electronic repulsion }\end{array}$ & Increase $\left[\mathrm{Na}^{+}\right]$ & Increase $\left[\mathrm{H}^{+}\right]$ & $\begin{array}{l}\text { Charge } \\
\text { shielding } \\
\text { OEG spacer }\end{array}$ \\
\hline
\end{tabular}




\section{Characterization of AuNPs by transmission electron microscopy (TEM)}

The AuNPs synthesized in-house and those bought from BBI Solutions (Cardiff, UK) were characterized by TEM. The sizes of AuNPs determined by the TEM images (Figure S1) were $13 \pm 1,50 \pm 2$, and $100 \pm 5 \mathrm{~nm}$ in diameter, respectively. All the AuNPs have the quite uniform sphere shape and the narrow size distribution, which are critical for high quality characterization by dynamic light scattering (DLS).

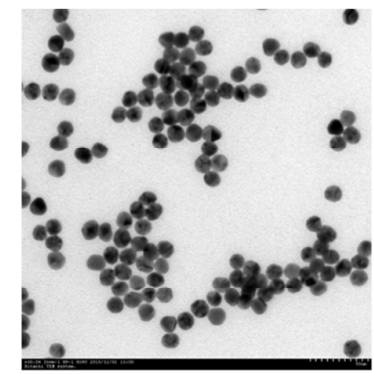

$13 \pm 1 \mathrm{~nm}$

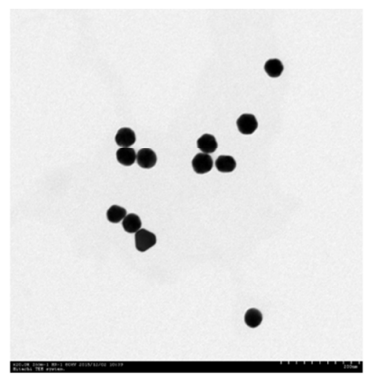

$50 \pm 2 \mathrm{~nm}$

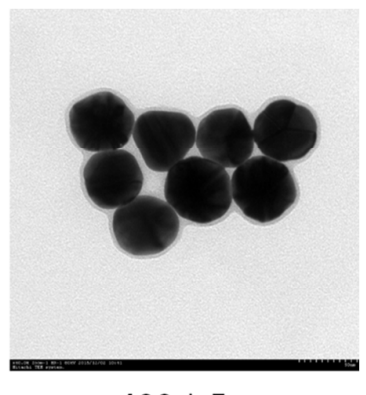

$100 \pm 5 \mathrm{~nm}$

Figure S1. Transmission electron microscope images of the AuNPs used in this study.

\section{Measuring the effects of OEG spacer length on immobilization kinetics}

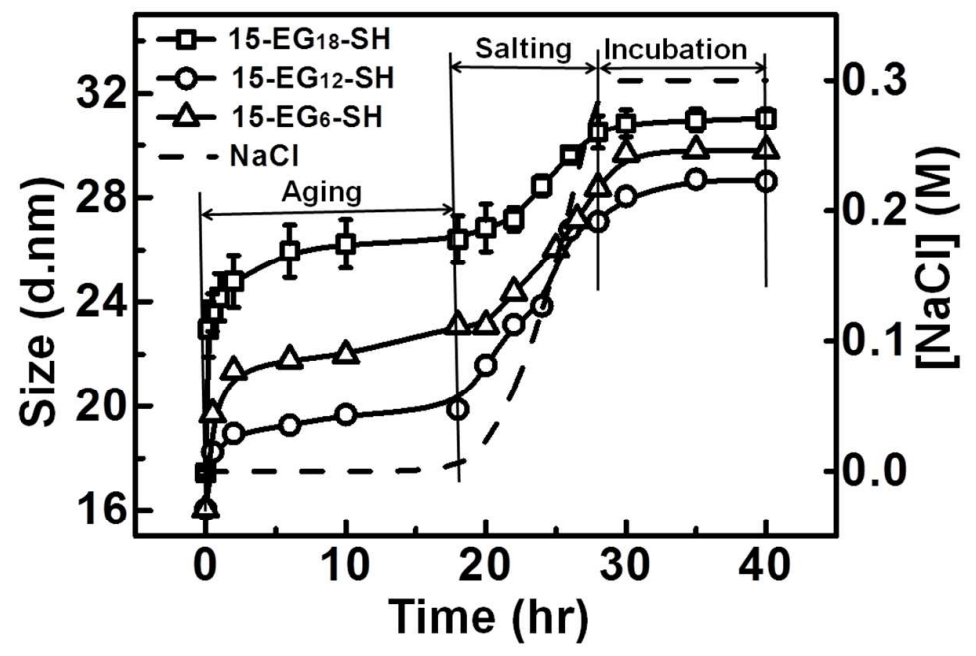

Figure S2. Kinetic measurements of the hydrodynamic sizes of DNA-AuNPs during the aging-salting process. The procedure includes the aging step ( 0 to $18 \mathrm{hr}$ ), the salting step (gradually increasing the $\mathrm{NaCl}$ concentration to $0.3 \mathrm{M}, 18$ to $28 \mathrm{hr}$ ), and further incubation from 28 to $40 \mathrm{hr}$. The dash line represents the $\mathrm{NaCl}$ concentration of the sample in the procedure. The DNA:AuNP molar ratios were 500. Error bars were calculated from three repeated measurements. 
3. Measuring the effects of $\mathbf{p H}$ on immobilization kinetics of $15-\mathrm{EG}_{18}-\mathrm{SH}$ on AuNP

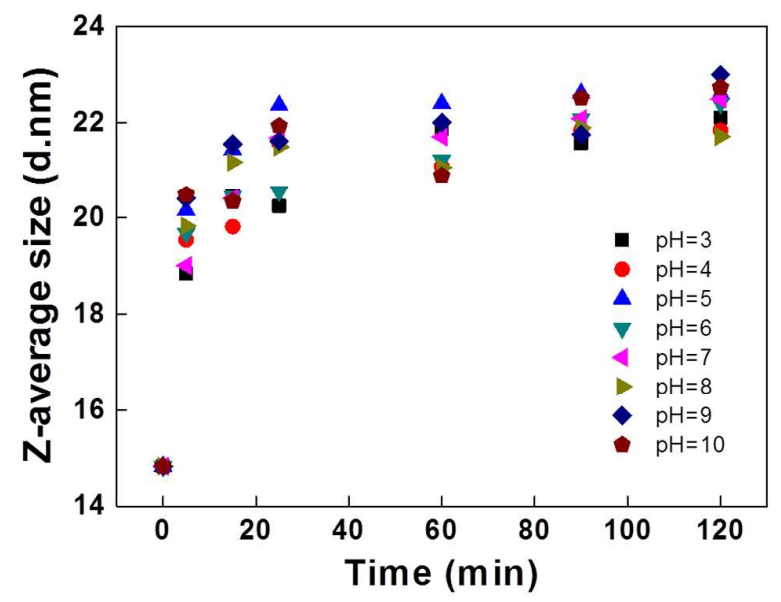

Figure S3. Kinetic measurements of the hydrodynamic sizes of $15-\mathrm{EG}_{18}$-SH-AuNPs during the $2 \mathrm{hr}$ incubation in $\mathrm{PB}$ at varied $\mathrm{pH}$. The $15-\mathrm{EG}_{18}-\mathrm{SH}$ :AuNP molar ratios were all 500 . The $\mathrm{pH}$ was adjusted by adding $\mathrm{HCl}$ or $\mathrm{NaOH}$.

\section{Measuring the effects of $\mathrm{NaCl}$}

(1) The order of addition of DNAs and $\mathrm{NaCl}$. If the DNAs in a buffer containing lower concentrations (e. g. $<100 \mathrm{mM}$ ) of $\mathrm{NaCl}$ were directly combined with AuNPs at a DNA:AuNP ratio of 500, the AuNPs remained stable, with UV-vis spectroscopy measurements after $2 \mathrm{hr}$ incubation equivalent to those of unmodified AuNPs. However, at lower DNA:AuNP ratios, lower concentrations of $\mathrm{NaCl}$ were required to secure the good stability of AuNPs. $\mathrm{NaCl}$ speeds up the adsorption kinetics of DNA, and the attached DNA in turn enhances the AuNP stability. However, $\mathrm{NaCl}$ also causes the aggregation of AuNPs by screening their surface charge, although the faster DNA adsorption kinetics allow for the use of higher concentrations of $\mathrm{NaCl}$. Therefore, it is critical to adjust the final salt concentration by adding $1 \mathrm{M} \mathrm{NaCl}$ after mixing the DNAs and AuNPs when the DNA:AuNP ratio is small or the desired final 
concentration of $\mathrm{NaCl}$ was high.

(2) DLS measurements. The DLS measurements (Figure S2A) clearly showed the great stability of DNA-AuNPs prepared by mixing with $15-\mathrm{EG}_{18}-\mathrm{SH}$ in $\mathrm{PB}$ at a DNA:AuNP ratio of 500, immediately followed by the addition of $1 \mathrm{M} \mathrm{NaCl}$ to adjust the final concentration of $\mathrm{NaCl}$. The most sensitive among the three DLS modes (intensity, volume, and number) for detecting particle aggregation is the intensity mode. The intensity, volume, and number of DLS is respectively proportional to $10^{6}$-, $10^{3}$-, and one-fold of the particle diameter. We only observed one narrow peak for each sample after $2 \mathrm{hr}$ incubation when plotted according to the intensity distribution (Figure S2A), indicating the great stability of the DNA-AuNPs prepared by the OEG spacer-based method. In addition, the polydispersity indexes (PDI) measured by DLS were quite small, suggesting uniform attachment of DNAs. 

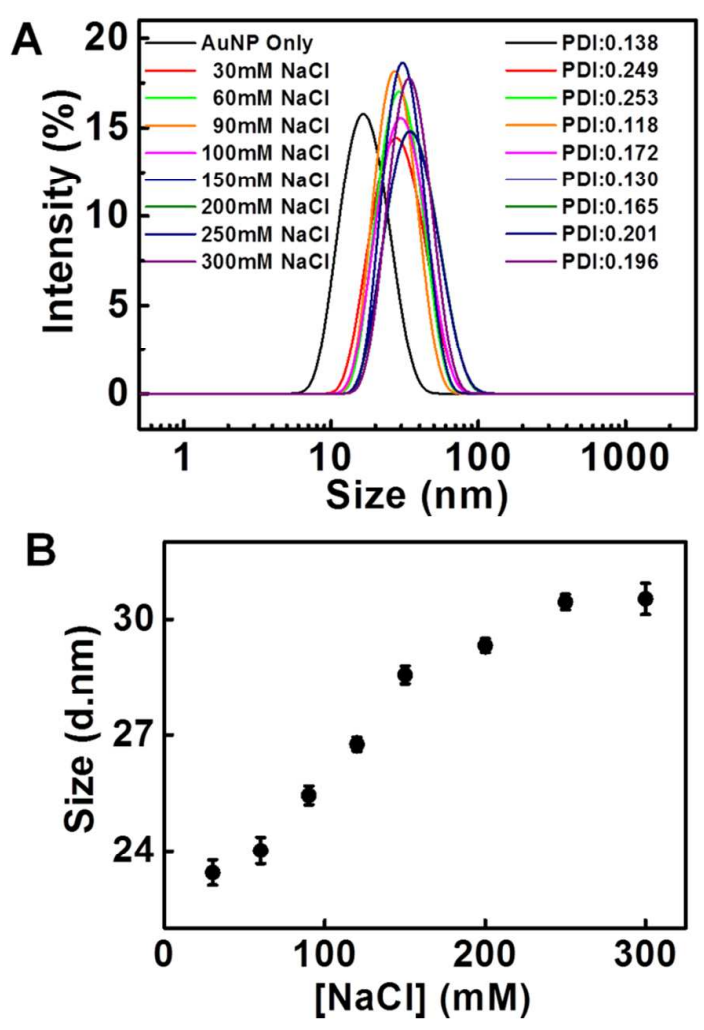

Figure S4. DLS measurements (A) of $13 \mathrm{~nm}$ AuNPs before and after $2 \mathrm{hr}$ incubation with $15-\mathrm{EG}_{18}-\mathrm{SH}$ in $\mathrm{PB}$ containing various concentrations of $\mathrm{NaCl}$ and the function between hydrodynamic size and the concentration of $\mathrm{NaCl}(\mathrm{B})$.
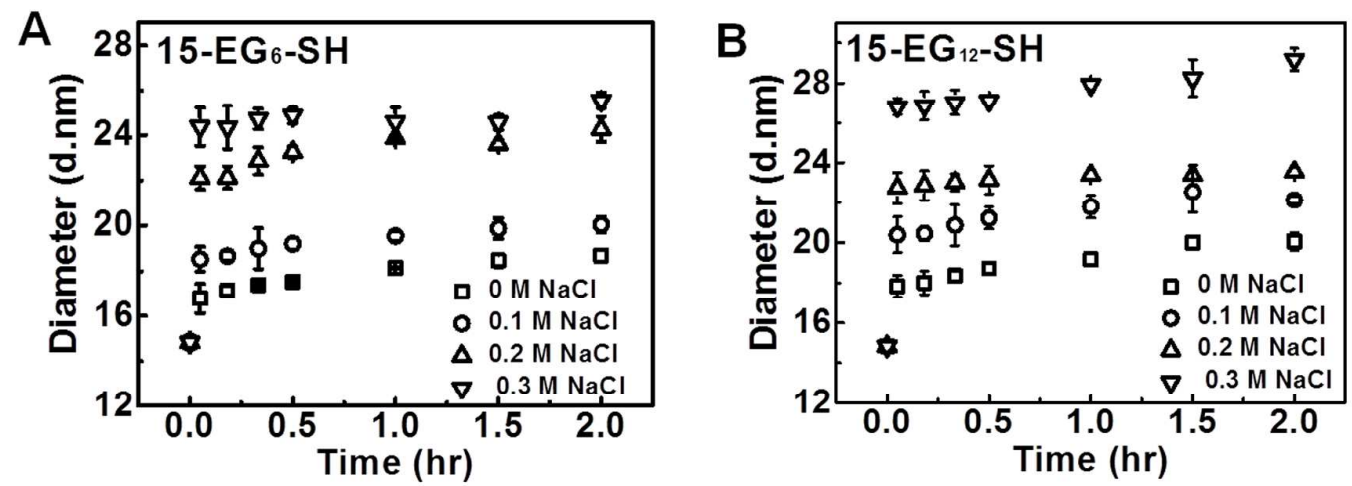

Figure S5. Kinetic size measurements of $15-\mathrm{EG}_{6}-\mathrm{SH}-\mathrm{AuNPs}$ (A) and $15-\mathrm{EG}_{12}-\mathrm{SH}-\mathrm{AuNPs}(\mathrm{B})$ during incubation in $\mathrm{PB}$ containing $0,0.1,0.2$, or $0.3 \mathrm{M}$ $\mathrm{NaCl}$. The DNA:AuNP molar ratios were 500. Error bars were calculated from three repeated measurements. 


\section{UV-vis spectra and DLS measurements of 13 and $50 \mathrm{~nm}$ AuNPs.}

UV-vis spectra and DLS measurements confirmed that the OEG spacer-assisted method was generally applicable to other DNA sequences (Supporting Information, Table S1) and other sizes of AuNPs. The UV-vis spectra of the DNA-AuNPs all overlapped with that of the unmodified AuNPs (both 13 and $50 \mathrm{~nm}$ ) in PB containing up to $150 \mathrm{mM} \mathrm{NaCl}$ (data not shown). A slight red-shift of the AuNP plasmon band was observed in $0.3 \mathrm{M} \mathrm{NaCl}$ (Figure 3C, Figure S6). For the DLS measurements, we only observed one narrow peak for each sample after $2 \mathrm{hr}$ incubation, even when plotted according to the intensity distribution (Figure S6), indicating the great stability of DNA-AuNPs prepared by the OEG spacer-assisted method. The PDIs of DNA-AuNPs measured by DLS were quite small for $13 \mathrm{~nm}$ AuNPs in PB /0.3 M $\mathrm{NaCl}$, while those of the $50 \mathrm{~nm}$ AuNPs were much greater for both unmodified AuNPs and DNA-AuNPs. 

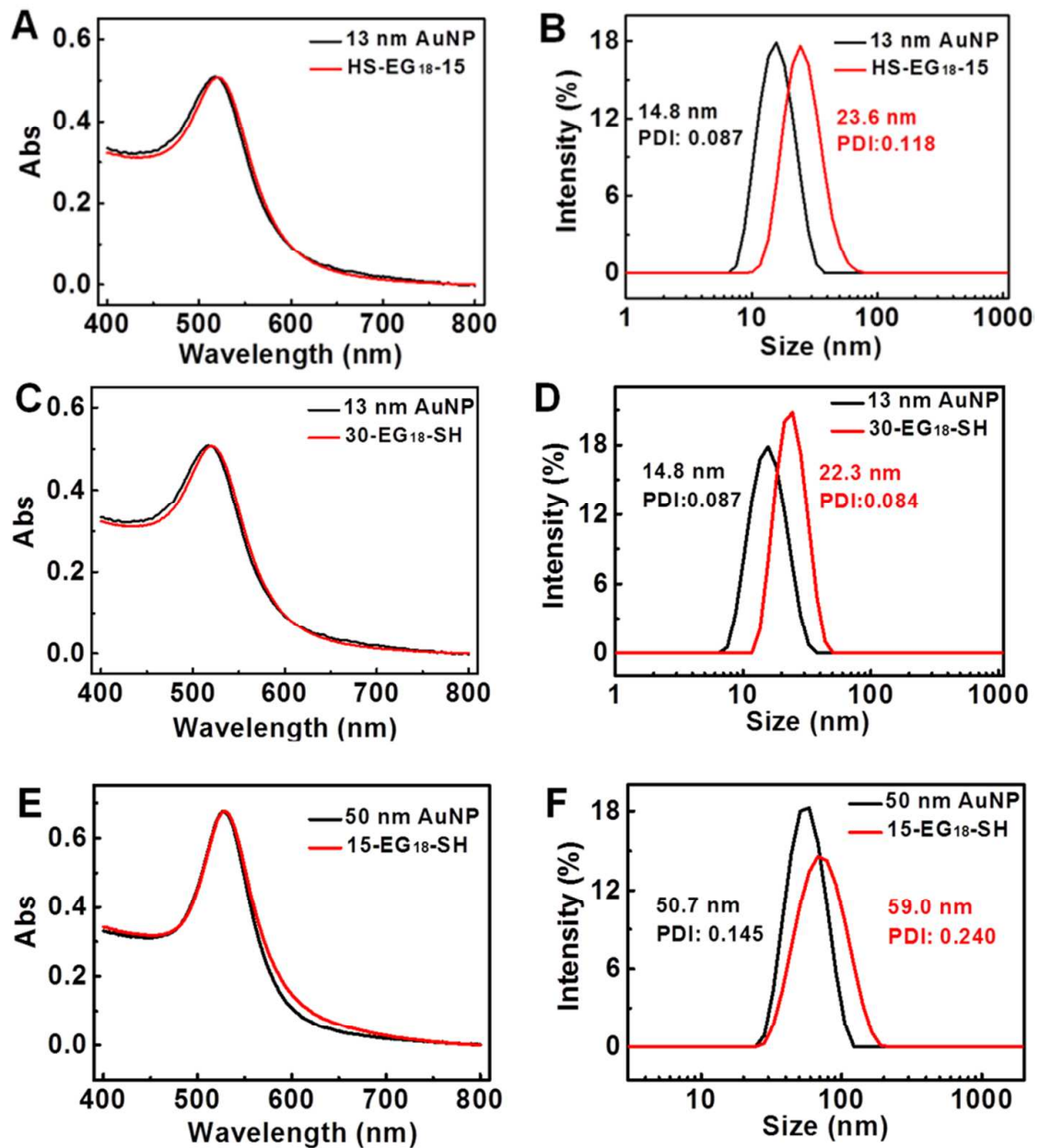

Figure S6. UV-vis absorption spectra (A, C, and E) and DLS measurements (B, D, and F) of DNA-modified and unmodified 13 and $50 \mathrm{~nm}$ AuNPs after $2 \mathrm{hr}$ incubation with $\mathrm{HS}-\mathrm{EG}_{18}-15,30-\mathrm{EG}_{18}-\mathrm{SH}$, and $15-\mathrm{EG}_{18}-\mathrm{SH}$ in $\mathrm{PB}$ containing $0.3 \mathrm{M} \mathrm{NaCl}$, respectively. 


\section{UV-vis spectra and DLS measurements of $100 \mathrm{~nm}$ AuNPs.}

We also observed a single narrow DLS peak and small PDIs for $100 \mathrm{~nm}$ DNA-AuNPs after $2 \mathrm{hr}$ incubation in $\mathrm{PB}$ with and without $0.1 \mathrm{M} \mathrm{NaCl}$ (Figure S7). The extinction peak intensity dropped slightly, indicating slight aggregation of AuNPs (Figure S7). However, significant aggregation of AuNPs occurred if no $15-\mathrm{EG}_{18}-\mathrm{SH}$ was added. This phenomenon was similar to what has been observed in low-pH based method. ${ }^{1}$ It should be noted that it is difficult to determine the stability of large AuNPs in high salt concentration based on color. It has been reported that large AuNPs that have been densely functionalized with DNA can undergo aggregation in the absence of target due to collective effects. ${ }^{2}$ Even hybridization of one or two DNA base-pairs on different AuNPs can lead to the formation of large aggregates.
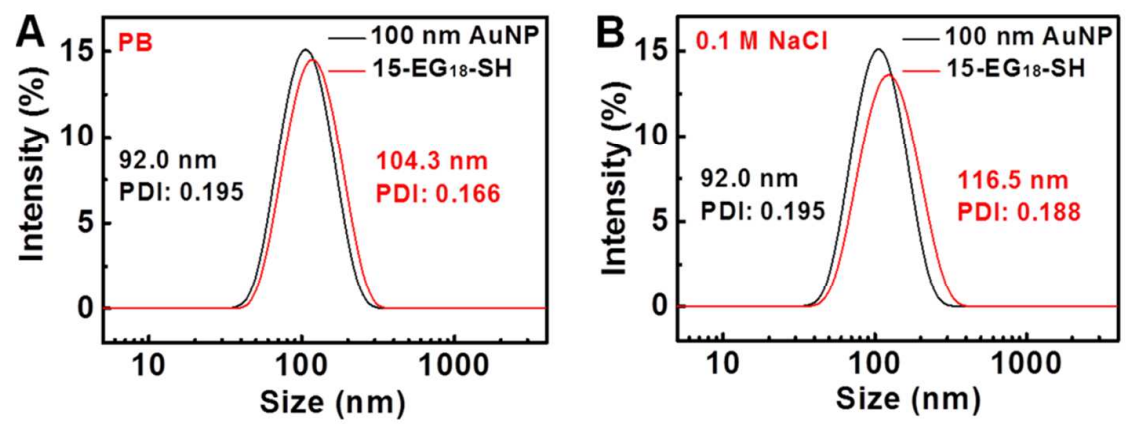

Figure S7. DLS measurements of $100 \mathrm{~nm}$ AuNPs before and after $2 \mathrm{hr}$ incubation with $15-\mathrm{EG}_{18}-\mathrm{SH}$ in $\mathrm{PB}$ without (A) or with $0.1 \mathrm{M} \mathrm{NaCl}(\mathrm{B})$. 


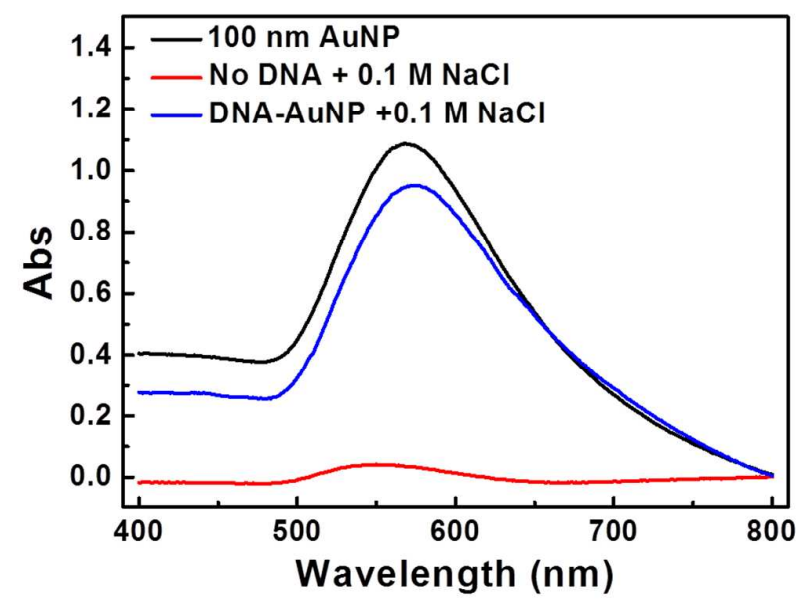

Figure S8. UV-vis absorption spectra of $100 \mathrm{~nm}$ AuNPs (black line), AuNPs loaded with $15-\mathrm{EG}_{18}$-SH prepared in $\mathrm{PB}$ containing $0.1 \mathrm{M} \mathrm{NaCl}$ (blue line), and unmodified AuNPs with $0.1 \mathrm{M} \mathrm{NaCl}$ (red line).

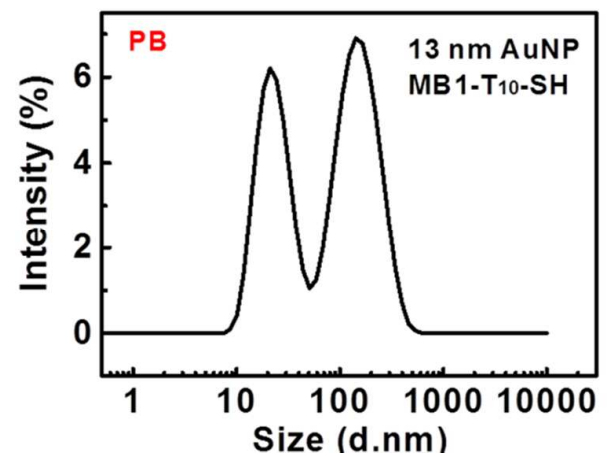

Figure S9. DLS measurements of AuNPs (13 nm) after $18 \mathrm{hr}$ aging with $\mathrm{MB} 1-\mathrm{T}_{10}-\mathrm{SH}$ in $\mathrm{PB}$ without $\mathrm{NaCl}$.

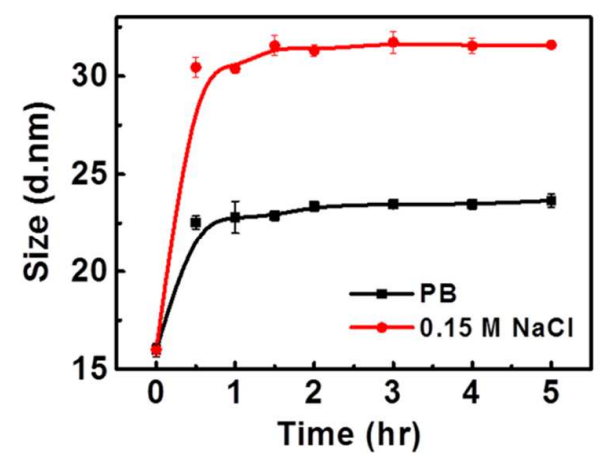

Figure S10. DLS measurements of AuNPs $(13 \mathrm{~nm})$ after mixing with $\mathrm{MB} 1-\mathrm{EG}_{18}-\mathrm{SH}$ in $\mathrm{PB}$ with or without $0.15 \mathrm{M} \mathrm{NaCl}$. 


\section{References}

1. Zhang, X.; Servos, M. R.; Liu, J., Instantaneous and Quantitative Functionalization of Gold Nanoparticles with Thiolated DNA Using a pH-Assisted and Surfactant-Free Route. J. Am. Chem. Soc. 2012, 134, 7266-7269.

2. Hurst, S. J.; Hill, H. D.; Mirkin, C. A., "Three-Dimensional Hybridization" with polyvalent DNA-gold nanoparticle conjugates. J. Am. Chem. Soc. 2008, 130, 12192-12200. 